MYERS Rodica, Cuando el sol caminaba por la tierra. Orígenes de la intermediación kallawaya, Ediciones Plural, La Paz, 2002, 156 p., bibl., ill., carte, tabl.

\title{
Mickael Brohan
}

\section{(2) OpenEdition}

Édition électronique

URL : https://journals.openedition.org/jsa/1614

DOI : 10.4000/jsa.1614

ISSN : 1957-7842

Éditeur

Société des américanistes

Édition imprimée

Date de publication : 5 juin 2003

Pagination : 236-239

ISSN : 0037-9174

\section{Référence électronique}

Mickael Brohan, « MYERS Rodica, Cuando el sol caminaba por la tierra. Orígenes de la intermediación kallawaya, Ediciones Plural, La Paz, 2002, 156 p., bibl., ill., carte, tabl. », Journal de la Société des américanistes [En ligne], 89-2 | 2003, mis en ligne le 05 novembre 2003, consulté le 04 septembre 2022. URL : http://journals.openedition.org/jsa/1614; DOI : https://doi.org/10.4000/jsa.1614

Ce document a été généré automatiquement le 4 septembre 2022

Tous droits réservés 


\title{
MYERS Rodica, Cuando el sol caminaba por la tierra. Orígenes de la intermediación kallawaya, Ediciones Plural, La Paz, 2002, 156 p., bibl., ill., carte, tabl.
}

\author{
Mickael Brohan
}

1 Les Kallawaya de Bolivie sont aujourd'hui bien connus d'un point de vue ethnographique, même si l'attention des chercheurs s'est très largement polarisée sur leur système rituel et sur l'activité thérapeutique à l'origine de leur renommée dans tout le continent sudaméricain. Cependant, ils continuent à être une "énigme ethnohistorique», pour reprendre l'expression $d u$ regretté Thierry Saignes, précurseur en matière d'historiographie kallawaya. C'est cette énigme que ce court ouvrage s'emploie à résoudre.

2 En s'appuyant sur des archives boliviennes, argentines et sévillanes, et sur des travaux archéologiques et ethnohistoriques, Rodica Meyers entend démontrer que les Kallawaya constituaient jadis la clef de voûte d'un grand réseau d'échanges pan-andin et transpiémontais. Loin de dater d'une époque récente, les fameux déplacements des thérapeutes kallawaya s'inscriraient, d'après l'auteur, dans la lignée d'une forme de mobilité ancienne qui aurait été plus générale et plus importante. De façon logique, l'ethnohistorienne se propose d'exposer les modalités de cette "intermédiation kallawaya » ainsi que ses transformations dans le temps, depuis l'époque préinca jusqu’à la période coloniale.

3 Après avoir rappelé, néanmoins sans se prononcer elle-même, les différentes hypothèses concernant la naissance du señorío dualiste kallawaya situé au nord-est du lac Titicaca, l'auteur présente l'espace indigène. Reprenant l'argument de plusieurs collègues spécialistes des Andes septentrionales, elle considère les capacités du milieu - qui, dans le cas kallawaya, sont favorables au développement d'activités agricoles et agro- 
pastorales, garantissant non seulement une autosuffisance économique mais aussi la production d'excédents agricoles importants - comme un facteur décisif à la mobilité et à la création-expansion d'un système d'échanges à longue distance. Ces déplacements ne semblent pas avoir été limités à la région kallawaya stricto sensu, c'est-à-dire à l'espace naturel situé au nord-est du lac Titicaca entre le río Suches, les punas d'Umapampa et les confins des llanos d'Apolo. Grâce à des moyens d'accès et de contrôle de produits et de biens provenant de régions voisines, plus précisément grâce au contrôle des camélidés permettant la circulation de caravanes marchandes et grâce à la présence des groupes Yungas à la croisée des hautes et des basses terres, ils ont pu être effectués jusqu'à l'aire circumlacustre, la côte occidentale, les oasis côtières chiliennes, le Nord-Ouest argentin et enfin la haute Amazonie. S'inspirant du concept d'«activité mobile giratoire» de Núñez et Dillehay, le modèle de mobilité kallawaya présenté ici permet d'insister sur l'idée de variations circonstancielles des déplacements et donc des réseaux de relations et d'échange. En d'autres termes, il s'agirait non pas de réseaux figés au cœur d'une aire d'occupation définitive mais d'un système d'échange inscrit dans une " aire d'action " aux limites fluctuantes (chapitres III et IV).

Le chapitre $\mathrm{V}$ est consacré à l'analyse des modalités de ce grand système d'échange. Deux niveaux de mobilité sont distingués : l'« intermédiation orientale » et l'« intermédiation transversale ». Le premier aurait lié la zone kallawaya au bas piémont amazonien via le contact entre les groupes Yungas et les groupes chuncho compris entre les rios Tuichi, Beni, Mapiri et Carabaya. Selon l'auteur, on échangeait du sel et des métaux provenant des hautes terres contre des biens amazoniens comme des plantes, des colorants ou des plumes. Bien argumentée, la démonstration est concluante, exception faite de la question du commerce de sel. Contrairement aux métaux, aucune preuve n'atteste en effet formellement que, par l'intermédiaire des Kallawaya, les groupes piémontais recevaient du sel provenant des hautes terres. En outre, si plusieurs de ces groupes semblent bien ne pas avoir disposé localement de sel, ce n'était pas le cas de tous et notamment pas celui des Chimane ${ }^{1}$. Au contraire, l'exploitation du sel par ce dernier groupe laisse entrevoir la possibilité d'un réseau d'échange de sel en provenance non pas des hautes terres mais du piémont amazonien. Complémentaire du premier niveau de mobilité, bien que d'une ampleur supérieure, l'« intermédiation transversale » aurait, toujours sous la coupe des Kallawaya, permis la circulation de produits amazoniens ou piémontais (plumes, plantes médicinales, hallucinogènes, coca, colorants), andins (or, argent, cuivre, étain, bronze, tissus, céramique) ou encore côtiers (poisson séché, coquillages) entre l'aire circumlacustre, la côte occidentale, les oasis côtières chiliennes, le Nord-Ouest argentin et la haute Amazonie. Notons que l'auteur insiste, avec raison, sur un fait aujourd'hui mieux connu: les réseaux d'échange à grande distance faisaient circuler non seulement des produits de première nécessité mais aussi des connaissances et des idéologies (essentiellement liées au monde liturgique) nécessaires à l'utilisation de nombre des produits échangés. Dans cette optique, elle se risque à quelques intéressantes comparaisons entre l'utilisation rituelle de produits amazoniens par les Tacana et par les Kallawaya (pp. 84-85). Ses incursions dans l'ethnologie comparative tacana-kallawaya thème que plusieurs spécialistes considèrent comme l'une des priorités des relations entre les hautes terres et les basses terres - sont néanmoins timides, faute sans doute de maitriser aussi complètement les deux ethnographies.

5 Vient enfin l'analyse des modifications de ce système d'échange et du rôle des Kallawaya sous l'Empire inca (chapitre VI) et la colonie (chapitre VII). L'auteur restitue clairement les stratégies inca et kallawaya. Souhaitant utiliser les réseaux commerciaux établis par 
les Kallawaya pour étendre et consolider sa domination, l'Inca établit des relations étroites avec ces derniers, comme il l'avait fait avec d'autres groupes de marchands aux confins de l'empire. Tout en plaçant des mitimaes, devant garantir un meilleur contrôle de la production et des routes d'échange, il laisse aux Kallawaya des prérogatives importantes et accorde des privilèges aux groupes et seigneurs locaux coopérant à son projet: l'indépendance administrative des Yungas, précieux intermédiaires avec les sociétés de la forêt, ou encore le fameux port en litière (à son égal) du seigneur kallawaya ayant assuré l'accès aux groupes piémontais boliviens et ayant ainsi contribué à la création de la province inca des Chuncho. Le détail de cette création est d'autant plus intéressant qu'il s'agit d'un fait relativement méconnu de l'historiographie inca et qui a très peu suscité l'intérêt des archéologues alors qu'il existe dans cette région de haute Amazonie plusieurs forteresses et une ancienne route pavée attribuées aux Incas. On regrettera néanmoins que Rodica Meyers mette trop l'accent sur la domination des groupes chuncho par l'Inca. Comme elle le rappelle, les Aguachile étaient bien cocaleros de l'Inca et les Araona lui payaient le tribut en or, argent et plumes, cependant que d'autres groupes pratiquaient l'orpaillage de rivière à son service mais sans doute, comme ailleurs dans le piémont, ces relations étaient autant, sinon davantage, négociées que subies par les groupes amazoniens. Comme l'attestent les chroniques, les Chuncho semblent en effet y avoir trouvé des avantages matériels et/ou symboliques, probable raison de leur concours : outre les très recherchés outils métalliques, des idoles en bronze et une mascapaïcha pour les Araona ${ }^{2}$ ou encore le port en litière pour les chefs aguachile ${ }^{3}$. Remarquons au passage que, contrairement à ce que constate l'auteur (pp. 117, 123 et sq.), les groupes de la famille linguistique takana, principales composantes de cette ancienne province chuncho, ne sont pas - ou plutôt ne sont plus - rattachés à la famille linguistique arawak mais à la famille pano.

6 Pendant la période coloniale, l'attitude des Kallawaya face aux nouveaux interlocuteurs ne change en rien : appui des caciques aux nouvelles autorités civiles et religieuses afin de conserver, voire d'augmenter, leurs privilèges, assistance aux conquistadores pour contacter les Chuncho. Faute d'intégration suffisante des produits agricoles kallawaya au marché colonial et suite à la rupture des relations avec les Chuncho, les Kallawaya ne parviennent pas à conserver leur rôle d'intermédiaires à moyenne ou longue distance. Ils se contentent donc jusqu'à présent de la seule et discrète (car longtemps interdite) activité thérapeutique comme moyen d'intermédiation. À ce propos, l'idée de l'auteur selon laquelle les guérisseurs kallawaya auraient continué à utiliser les routes empruntées par leurs ancêtres pour gagner l'Équateur, la côte péruvienne, l'aire circumlacustre, le Chili et le Nord-Ouest argentin (p.68) - on pourrait peut-être ajouter le piémont du Tuichi et du haut Beni, puisque les thérapeutes kallawaya visitaient encore cette région très récemment - est intéressante bien qu'elle ne soit que postulée et aucunement démontrée.

7 S'il n'épuise pas le sujet, cet ouvrage bien documenté et bien illustré constitue, en dépit de quelques omissions et de quelques erreurs, un apport solide à la connaissance ethnohistorique des Kallawaya et, plus généralement, à la compréhension des grands réseaux d'échanges pan-andins et transpiémontais. Espérons pour conclure que le développement de l'archéologie dans la zone kallawaya et, plus largement, dans les régions andine et piémontaise permettra, avec une véritable ethnologie comparative kallawaya-tacana, de mieux comprendre à terme la nature des complexes interactions ayant eu jadis cours dans cette région charnière. 


\section{NOTES}

1. Voir Isabelle Daillant, "Porque ahí parió la mujer de Dios. La salina de Los Chimanes y la destrucción de sus petroglifos ", Sociedad de investigación del arte rupestre de Bolivia, Boletín 11, 1997, pp. 53-67.

2. Voir Victor Manuel Maurtua, Juicio de límites entre el Perú y Bolivia, Imprenta de Henrich y Comp., Barcelona, 1906, XII, pp. 21, 31, 58-59.

3. Voir France-Marie Renard-Casevitz et al., L'Inca, l'Espagnol et les sauvages. Rapports entre les sociétés amazoniennes et andines $d u X V^{e}$ au XVII siècle, Édition Recherches sur les Civilisations, Paris, 1986, p. 115.

\section{AUTEURS}

\section{MICKAEL BROHAN}

Institut français d'études andines 